\title{
Solid Recycling of an AZ31 Mg Alloy with a Vapor Deposition Coating Layer of High Purity Mg
}

\author{
Yasumasa Chino $^{1}$, Atsuyuki Yamamoto ${ }^{2}$, Hajime Iwasaki ${ }^{2}$, Mamoru Mabuchi $^{1}$ \\ and Harushige Tsubakino ${ }^{2}$ \\ ${ }^{1}$ Institute for Structural and Engineering Materials, National Institute of Advanced Industrial Science and Technology, \\ Nagoya 463-8560, Japan \\ ${ }^{2}$ Division of Materials Science and Engineering, Graduate School of Himeji Institute of Technology, Himeji 671-2201, Japan
}

\begin{abstract}
Solid recycling of AZ31 Mg alloy with vapor deposition coating layer of high purity $\mathrm{Mg}$ was evaluated. In the open die forging experiments, two AZ31 Mg alloy specimens with the pure $\mathrm{Mg}$ deposition coating layer of the $30 \mu \mathrm{m}$ in thickness were forged. The specimens were sufficiently bonded by forging at $673 \mathrm{~K}$. Furthermore, the elements (Al and Zn) of the AZ31 substrate diffused up to the center of the pure $\mathrm{Mg}$ deposition coating layer. The theoretical analysis in which only the lattice diffusion was considered showed that the elements in the AZ31 substrate cannot diffuse to the center of the pure $\mathrm{Mg}$ deposition coating layer. The grain boundary diffusion coefficient of $\mathrm{Mg}$ at $673 \mathrm{~K}$ is about 25 times larger than the lattice diffusion coefficient. Therefore, it is suggested that the grain boundary diffusion enhanced by grain refinement due to hot forging largely contributes to the solid state bonding of the forged specimens. Also, the solid recycled specimen was fabricated from the AZ31 Mg substrate with pure Mg deposition coating layer by hot extrusion at $673 \mathrm{~K}$. The solid recycled specimen showed almost the same tensile properties as the virgin extruded specimen. This is probably related not only to the grain boundary diffusion enhanced due to grain refinement, but also severe plastic deformation by hot extrusion.
\end{abstract}

(Received October 18, 2002; Accepted January 20, 2003)

Keywords: magnesium alloy, deposition coating, solid recycling process, hot extrusion, grain refinement, grain boundary diffusion

\section{Introduction}

$\mathrm{Mg}$ alloys are currently the lightest alloys used as structural metals and some $\mathrm{Mg}$ products have been applied for structural uses such as automobile parts and electric appliance cases. $^{1,2)}$ In order to obtain further demands of $\mathrm{Mg}$ alloys, it is necessary not only to attain good characteristics (high strength, high ductility, high corrosion resistance, creep resistance and so on), but also to develop useful recycling processes. ${ }^{3)}$ Some recycling processes for $\mathrm{Mg}$ alloys, for example, remelting, ${ }^{4,5)}$ electrorefining in molten salt ${ }^{6)}$ and vacuum distillation, ${ }^{7)}$ have been proposed. The "in-house scraps" have been recycled by the remelting processes. ${ }^{4,5)}$ However, when the scraps coated with nickel, cupper and so on are recycled, contamination of nickel, cupper and iron causes a significant increase in corrosion rate in recycled $\mathrm{Mg}$ products. $\left.{ }^{4,8}\right)$ Therefore, it is important to avoid the contamination for recycling of $\mathrm{Mg}$ alloys.

Recently, the "solid recycling" process has been proposed as a new recycling method for metal scraps. ${ }^{9-11)}$ In the process, metal scraps are recycled by hot consolidation using hot working such as hot extrusion. It should be noted that remelting is not required in the solid recycling process. Furthermore, the solid recycled Mg alloy shows high strength due to grain refinement and homogeneous dispersion of the oxide film on the surface of scraps. ${ }^{9)}$ However, for the solid recycling as well as the above recycling processes, application of the recycling process to $\mathrm{Mg}$ scraps is limited to the clean scraps such as "in-house scraps". When the surface treated $\mathrm{Mg}$ scraps are recycled by solid recycling process, complicated pretreatments such as elaborate scrubbing are needed for elimination of the surface coating.

Recently, Yamamoto et al. ${ }^{12,13)}$ developed a new method for surface treatment of $\mathrm{Mg}$ alloys by deposition coating of high purity $\mathrm{Mg}$ which shows high corrosion resistance. ${ }^{14)} \mathrm{Mg}$ products with the $\mathrm{Mg}$ deposition coating will show high recycling ability because of no contamination.

In the present study, the conditions for solid recycling of AZ31 Mg products with the pure $\mathrm{Mg}$ deposition coating layer are investigated from the viewpoint of diffusion of the elements of AZ31 to the pure Mg deposition coating layer. In addition, mechanical properties of the solid recycled specimen are evaluated by tensile tests.

\section{Experimental Procedure}

An AZ31 (Mg-3 mass\%Al-1 mass\%Zn-0.15 mass\%Mn) $\mathrm{Mg}$ alloy specimen with the dimension of $10 \mathrm{~mm} \times 10 \mathrm{~mm} \times$ $6 \mathrm{~mm}$ was used as a substrate plate. Also, pure $\mathrm{Mg}$ with three nine purity was used as an evaporation source. A horizontal vacuum furnace which had two heating zones was used for deposition of pure $\mathrm{Mg}$. Pure Mg was heated at about $973 \mathrm{~K}$ in the higher temperature zone, while the substrate plate was held at about $623 \mathrm{~K}$ in the lower temperature zone. Evaporation and deposition coating were carried out on the substrate plate for $7.2 \mathrm{ks}$ under about $1 \times 10^{-3} \mathrm{~Pa}$ in vacuum. Then, the deposition coated specimen was turned over and the evaporation and the deposition coating were carried out again to homogenize the thickness of the deposition coating. The cross section of the deposition coated specimen is shown in Fig. 1. The average thickness of the coating was $30 \mu \mathrm{m}$.

Open die forging tests were carried out to investigate diffusion to the pure $\mathrm{Mg}$ deposition coating layer. The deposition coated specimen was put on the other and the two specimens with a total thickness of $12 \mathrm{~mm}$ was forged to a total thickness of $5 \mathrm{~mm}$ at a cross head speed of $1.2 \times 10^{-2} \mathrm{~mm} / \mathrm{s}$, that is, the draft was set to be 0.6 and the forging time was set to be $600 \mathrm{~s}$. The forging temperature was 


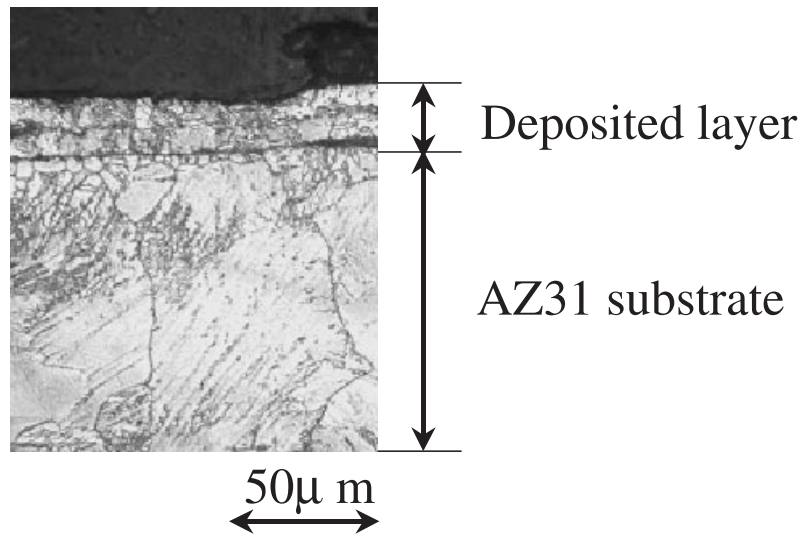

Fig. 1 The cross section of the deposition coated AZ31 Mg alloy specimen.

set to be $503 \mathrm{~K}$ and $673 \mathrm{~K}$ because the machined chips of AZ31 Mg alloy could be consolidated by hot extrusion at more than $503 \mathrm{~K}$ in the previous work. ${ }^{11)}$

Distributions of $\mathrm{Mg}, \mathrm{Al}$ and $\mathrm{Zn}$ concentration at the interface of the forged two specimens were investigated by EPMA analysis. At the analysis, the line profiles perpendicular to the bonded interface of the forged specimen were measured.

Furthermore, hot extrusion of the deposition coated specimens was carried out. The deposited specimens were filled into a container with a diameter of $40 \mathrm{~mm}$ and then extruded at $673 \mathrm{~K}$ with an extrusion ratio of $5: 1$ in air. A cross head speed of ram was set to be $10^{-2} \mathrm{~mm} / \mathrm{s}$. For comparison, extrusions were processed from the AZ31 substrate plates without deposition coating under the same extrusion conditions. In the present study, extrusions from the deposition coated specimens are called the solid recycled specimens and those from substrate plates without deposition coating are called the virgin extruded specimens.

Tensile tests at room temperature were carried out at a strain rate of $1.7 \times 10^{-3} \mathrm{~s}^{-1}$. The tested specimens had a gauge length of $10 \mathrm{~mm}$ and a gauge diameter of $2.5 \mathrm{~mm}$. The tensile axis was parallel to the extrusion direction. A metallographic investigation was carried out by optical and scanning electron microscopies. The grain size of the specimens was measured by optical microscopy using the linear intercept method.

\section{Results and Discussion}

\subsection{Solid recycling by open die forging}

Figure 2 shows the distributions of $\mathrm{Mg}, \mathrm{Al}$ and $\mathrm{Zn}$ concentration at the interface of the two specimens forged at $503 \mathrm{~K}$. The deposition coating layer, whose initial thickness was about $60 \mu \mathrm{m}$, was compressed to about $30 \mu \mathrm{m}$ by the open die forging. At the center of the deposition coating layer, the concentration of $\mathrm{Mg}$ suddenly decreased. This indicates that the bonding between the specimens forged at $503 \mathrm{~K}$ is not sufficient. Besides, an abrupt increase in $\mathrm{Mg}$ concentration and a decrease in $\mathrm{Al}$ and $\mathrm{Zn}$ concentrations were observed at the interface between the deposition coating layer and the AZ31 substrate. Clearly, the elements of $\mathrm{Al}$ and $\mathrm{Zn}$ in AZ31 scarcely diffused into the deposition coating (a)

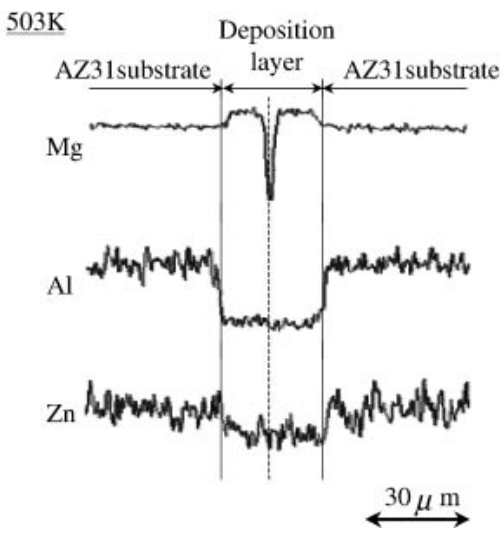

(b)

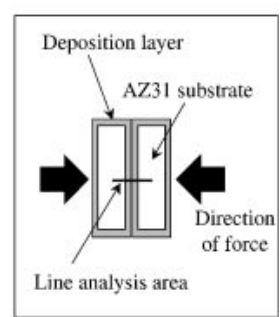

Fig. 2 Distributions of $\mathrm{Mg}, \mathrm{Al}$ and $\mathrm{Zn}$ concentration at the interface of AZ31 Mg alloy with $\mathrm{Mg}$ deposition coating layer forged at $503 \mathrm{~K}$ (a) and schematic view of the open die forging test (b).

$673 \mathrm{~K}$

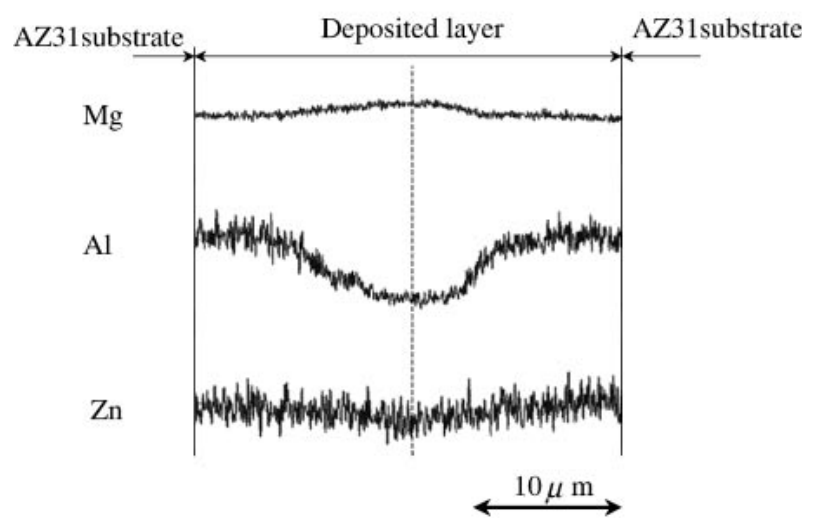

Fig. 3 Distributions of $\mathrm{Mg}, \mathrm{Al}$ and $\mathrm{Zn}$ concentration at the interface of AZ31 Mg alloy with $\mathrm{Mg}$ deposition coating layer forged at $673 \mathrm{~K}$.

layer of pure $\mathrm{Mg}$ in the case of forging at $503 \mathrm{~K}$.

Distributions of $\mathrm{Mg}, \mathrm{Al}$ and $\mathrm{Zn}$ concentration at the interface of the two specimens forged at $673 \mathrm{~K}$ are shown in Fig. 3, respectively. The thickness of the deposition coating layer was compressed to about $30 \mu \mathrm{m}$ by forging. It can be seen that the elements of $\mathrm{Al}$ and $\mathrm{Zn}$ in AZ31 diffused into the deposition coating layer of pure $\mathrm{Mg}$ by forging at $673 \mathrm{~K}$, although the concentration gradient of $\mathrm{Al}$ was observed, suggesting that the bonding between the specimens forged at $673 \mathrm{~K}$ is relatively sufficient.

Fukumoto et al. ${ }^{15)}$ proposed the utilization of hot pressing method for improvement of bonding between high purity $\mathrm{Mg}$ deposition coating layer and $\mathrm{Mg}$ alloy. They estimated the concentration distribution of $\mathrm{Mg}$ between the deposition coating layer and the substrate from one-dimensional selfdiffusion in two semi-infinite slabs ${ }^{16)}$ given by

$$
C=C_{0}+\frac{C_{1}-C_{0}}{2}\left[1+\operatorname{erf}\left(\frac{x}{2 \sqrt{D t}}\right)\right]
$$

where $C$ is the concentration of each element in the pure $\mathrm{Mg}$ layer, $C_{0}$ is the initial concentration of each element in the substrate, $C_{1}$ is the initial concentration in the deposition coating layer and $D$ is the diffusion coefficient of each element. In order to understand the concentration gradient 
(a) $\mathrm{Mg}$

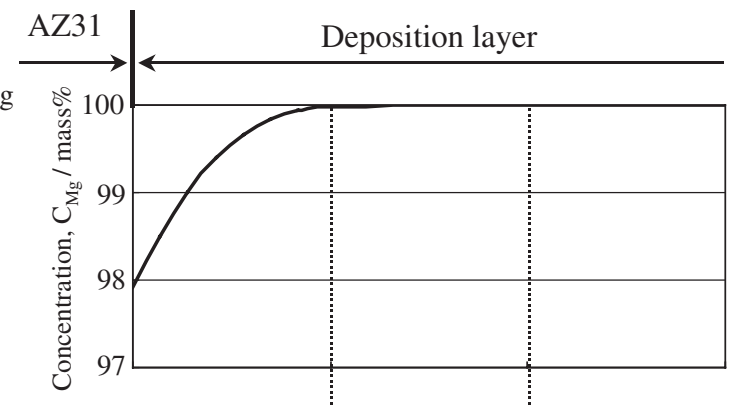

(b) $\mathrm{Al}$

(c) $\mathrm{Zn}$

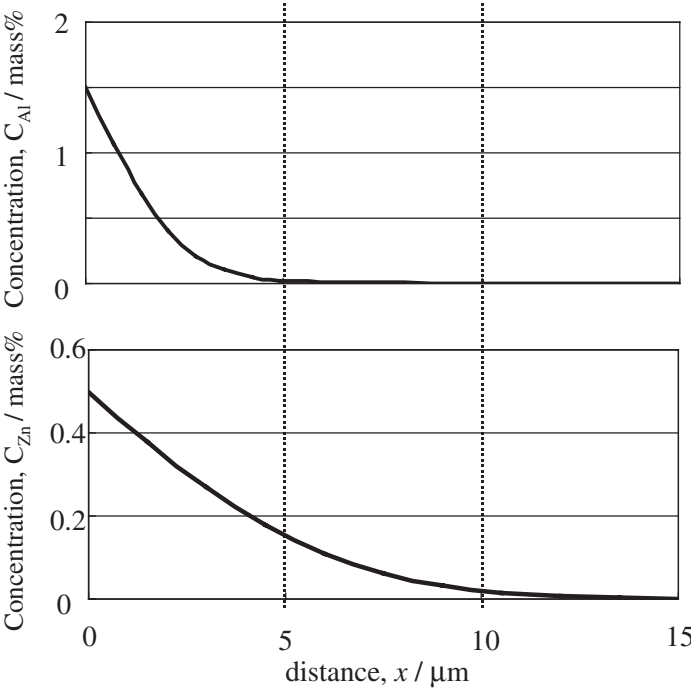

Fig. 4 Calculated distributions of $\mathrm{Mg}, \mathrm{Al}$ and $\mathrm{Zn}$ concentration at the interface of AZ31 Mg alloy with $\mathrm{Mg}$ deposition coating layer at $673 \mathrm{~K}$; (a) $\mathrm{Mg}$, (b) $\mathrm{Al}$, (c) $\mathrm{Zn}$.

shown in Fig. 3, distributions of $\mathrm{Mg}, \mathrm{Al}$ and $\mathrm{Zn}$ concentration in the deposition coating layer were estimated using the eq. (1), in which diffusions of $\mathrm{Al}$ and $\mathrm{Zn}$ in $\mathrm{Mg}$ and $\mathrm{Mg}$ in $\mathrm{Mg}$ (self-lattice diffusion) were evaluated. Figure 4 shows the calculated concentration distributions of each element in the pure $\mathrm{Mg}$ deposition coating layer at $673 \mathrm{~K}$ after $600 \mathrm{~s}$, where the diffusion coefficients of $\mathrm{Al}$ and $\mathrm{Zn}$ in $\mathrm{Mg}$ at $673 \mathrm{~K}$ are $3.01 \times 10^{-15} \mathrm{~m}^{2} / \mathrm{s}$ and $1.96 \times 10^{-14} \mathrm{~m}^{2} / \mathrm{s}$, respectively ${ }^{17)}$ and the self-diffusion coefficient in $\mathrm{Mg}$ at $673 \mathrm{~K}$ is $3.28 \times 10^{-15} \mathrm{~m}^{2} / \mathrm{s} .{ }^{18)}$ Concerning to $\mathrm{Mg}$ and $\mathrm{Al}$, the concentration gradient distributes within only $5 \mu \mathrm{m}$ from the interface. This indicates that the lattice diffusion is not a dominant factor which affects the concentration distribution in the deposition coating layer during open die forging at $673 \mathrm{~K}$.

It is well known that for wrought alloys with high dislocation density, the dislocation core diffusion accelerates solid state bonding. ${ }^{19)}$ Besides, the grain boundary diffusion accelerates solid state bonding, in particular, for fine-grained metals. ${ }^{20)}$ Hence, the dominant diffusion process of solid state bonding in the solid recycling may be the dislocation core diffusion or the grain boundary diffusion. The contribution of each diffusion process may be estimated using the effective diffusion concept. When both the lattice diffusion and the dislocation core diffusion of $\mathrm{Mg}$ are considered, the effective diffusion coefficient may be given by

$$
D_{\text {eff(c) }}=D_{\mathrm{o}} \exp \left(-Q_{\mathrm{v}} / R T\right)+a \rho D_{\mathrm{co}} \exp \left(-Q_{\mathrm{c}} / R T\right)
$$

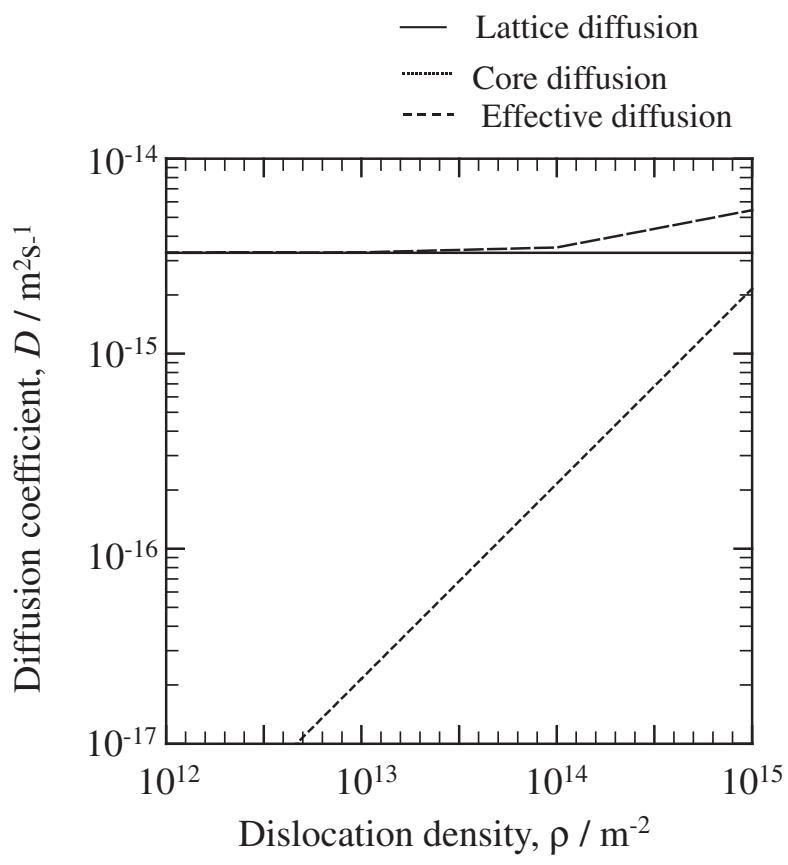

Fig. 5 The variation in calculated diffusion coefficients of magnesium at $673 \mathrm{~K}$ as a function of dislocation density.

where $D_{\text {eff(c) }}$ is the effective diffusion coefficient concerning to the lattice diffusion and the dislocation core diffusion, $D_{\mathrm{o}}$ is the pre-exponential of the lattice diffusion coefficient $\left(=1.8 \times 10^{-4} \mathrm{~m}^{2} / \mathrm{s}\right), Q_{\mathrm{v}}$ is the activation energy of the lattice diffusion $(=135 \mathrm{~kJ} / \mathrm{mol}), a$ is the cross sectional area of the dislocation core, $\rho$ is the dislocation density, $D_{\text {co }}$ is the preexponential of the dislocation core diffusion coefficient $\left(a D_{\text {co }}=3 \times 10^{-23} \mathrm{~m}^{4} / \mathrm{s}\right), Q_{\mathrm{c}}$ is the activation energy of the dislocation core diffusion $(=92 \mathrm{~kJ} / \mathrm{mol})$ and $R$ is a gas constant $\left.(=8.314 \mathrm{~J} / \mathrm{molK}) .{ }^{18,19}\right)$ Figure 5 shows the variation in diffusion coefficients of $\mathrm{Mg}$ at $673 \mathrm{~K}$ as a function of dislocation density. In general, the dislocation density of wrought metals is from $10^{12}$ to $10^{15} / \mathrm{m}^{2}$. ${ }^{21)}$ Inspection of Fig. 5 shows that the dislocation core diffusion is not effective even at the high dislocation density of $10^{15} \mathrm{~m}^{-2}$.

On the other hand, the effective diffusion coefficient concerning to the lattice diffusion and the grain boundary diffusion of $\mathrm{Mg}$ may be given by

$$
D_{\text {eff(b) }}=D_{\mathrm{o}} \exp \left(-Q_{\mathrm{v}} / R T\right)+(\pi \delta / d) D_{\text {bo }} \exp \left(-Q_{\mathrm{b}} / R T\right)
$$

where $D_{\text {eff(b) }}$ is the effective diffusion coefficient concerning to the lattice diffusion and the grain boundary diffusion, $\delta$ is the effective thickness of the boundary, $d$ is the grain size, $D_{\text {bo }}$ is the pre-exponential of the grain boundary diffusion coefficient $\left(\delta D_{\mathrm{co}}=5 \times 10^{-12} \mathrm{~m}^{3} / \mathrm{s}\right)$ and $Q_{\mathrm{b}}$ is the activation energy of the grain boundary diffusion $(=92 \mathrm{~kJ} / \mathrm{mol}){ }^{18,19)}$ Figure 6 shows the variation in calculated diffusion coefficients of $\mathrm{Mg}$ at $673 \mathrm{~K}$ as a function of grain size. It should be noted that the grain boundary diffusion is dominant when the grain size is less than $300 \mu \mathrm{m}$. The grain size of the specimens forged at $673 \mathrm{~K}$ was $14 \mu \mathrm{m}$, which was almost the same as that of the solid recycled specimen shown in Fig. 8. The grain boundary diffusion coefficient at the grain size of $14 \mu \mathrm{m}$ is $8.2 \times 10^{-14} \mathrm{~m}^{2} / \mathrm{s}$. This value is about 25 times larger than the 


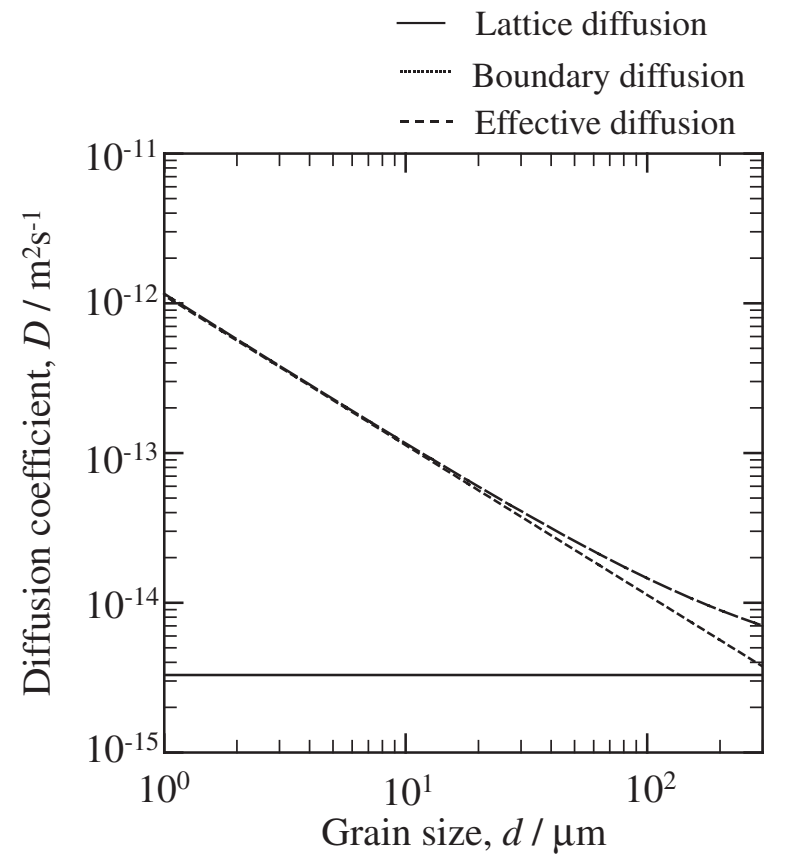

Fig. 6 The variation in calculated diffusion coefficients of magnesium at $673 \mathrm{~K}$ as a function of grain size.

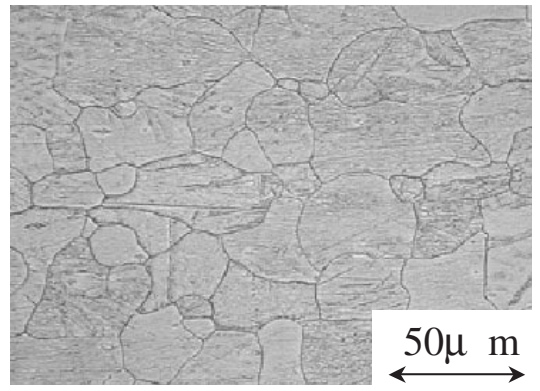

Fig. 7 Microstructure of the pre-extruded AZ31 Mg specimen.

Table 1 Tensile properties at room temperature and the grain size of the solid recycled AZ31 $\mathrm{Mg}$ alloy and the virgin extruded AZ31 Mg alloy.

\begin{tabular}{ccccc}
\hline Alloy & $\begin{array}{c}\text { Ultimate tensile } \\
\text { strength }(\mathrm{MPa})\end{array}$ & $\begin{array}{c}0.2 \% \text { Proof } \\
\text { stress }(\mathrm{MPa})\end{array}$ & $\begin{array}{c}\text { Elongation to } \\
\text { failure }(\%)\end{array}$ & $\begin{array}{c}\text { Grain size } \\
(\mu \mathrm{m})\end{array}$ \\
\hline $\begin{array}{c}\text { Solid recycled } \\
\mathrm{Mg} \text { alloy }\end{array}$ & 268 & 195 & 14 & 13.5 \\
\hline $\begin{array}{c}\text { Virgin extruded } \\
\mathrm{Mg} \text { alloy }\end{array}$ & 279 & 203 & 18 & 12.4 \\
\hline
\end{tabular}

(a)

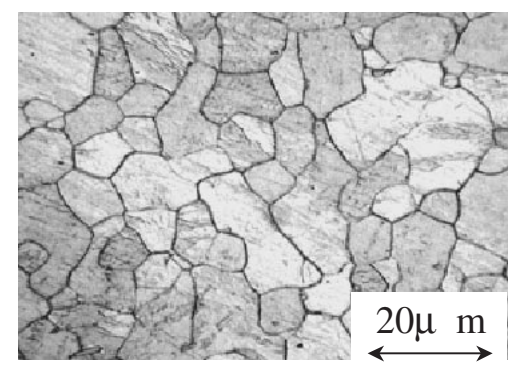

(b)

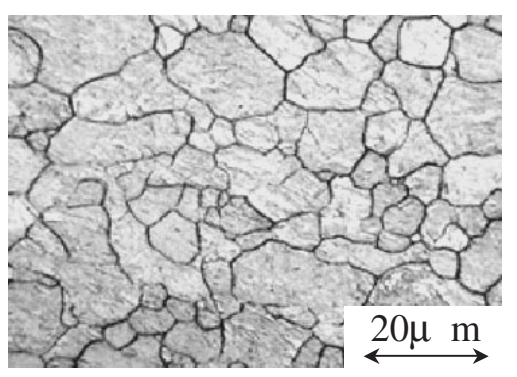

Fig. 8 Microstructures of AZ31 Mg alloy for the solid recycled specimen (a) and the virgin extruded specimen (b).

lattice diffusion coefficient of $\mathrm{Mg}$ at $673 \mathrm{~K}$. Therefore, it is suggested that the grain boundary diffusion largely contributes to the solid state bonding of the forged specimens and to the concentration distributions in the pure $\mathrm{Mg}$ deposition coating layer. The previous works ${ }^{9,22)}$ showed that a small grain size can be attained by hot working without any additional treatments for $\mathrm{Mg}$ alloy. It is noted that grain refinement due to hot deformation plays an important role in the solid recycling process because the grain boundary diffusion contributing to the solid state bonding is enhanced by grain refinement.

\subsection{Solid recycling by extrusion}

Solid recycling using hot extrusion was carried out on the AZ31 alloy with $\mathrm{Mg}$ deposition coating layer, where the extrusion temperature was $673 \mathrm{~K}$ and the ram speed was $10^{-2} \mathrm{~mm} / \mathrm{s}$. Microstructure of the AZ31 prior to the solid recycling process is shown in Fig. 7. The grain size was $37 \mu \mathrm{m}$.

Microstructures of the solid recycled specimen (b) and the virgin extruded specimen (b) are shown in Fig. 8, respectively. A small grain size of about $13 \mu \mathrm{m}$ was obtained for both the solid recycled specimen and the virgin extruded specimen. The grain size is almost the same as that of the specimen forged at $673 \mathrm{~K}$.

Mechanical properties of the solid recycled specimen and the virgin extruded specimen by tensile tests are summarized in Table 1, respectively. The solid recycled specimen exhibited the ultimate tensile strength of $268 \mathrm{MPa}, 0.2 \%$ proof stress of $195 \mathrm{MPa}$ and elongation to failure of $14 \%$, and the virgin extruded specimen showed the ultimate tensile strength of $279 \mathrm{MPa}, 0.2 \%$ proof stress of $203 \mathrm{MPa}$ and elongation to failure of $18 \%$. Thus, the solid recycled specimen showed almost the same tensile properties as the virgin extruded specimen. This is probably related not only to the grain boundary diffusion enhanced due to grain refinement, but also plastic deformation by hot extrusion because severe plastic deformation is given by hot extrusion, compared to the forging. To quantitatively understand effects of plastic deformation on the solid state bonding in solid recycling process, further research is needed. Anyway, it is conclusively demonstrated that AZ31 Mg alloy scraps with pure $\mathrm{Mg}$ deposition coating layer can be recycled by hot extrusion at $673 \mathrm{~K}$. 


\section{Conclusions}

Solid recycling of AZ31 Mg alloy with vapor deposition coating layer of high purity $\mathrm{Mg}$ was conducted by hot forging and extrusion. The results are summarized as follows.

(1) The specimens with the pure $\mathrm{Mg}$ deposition coating layer of $30 \mu \mathrm{m}$ thickness were bonded by open die forging at $673 \mathrm{~K}$. Elements of $\mathrm{Al}$ and $\mathrm{Zn}$ in $\mathrm{AZ31}$ diffused to the center of the $\mathrm{Mg}$ deposition coating layer.

(2) The theoretical analysis showed that the grain boundary diffusion coefficient at $673 \mathrm{~K}$ is about 25 times larger than the lattice diffusion coefficient for $\mathrm{Mg}$. It is therefore suggested that the grain boundary diffusion largely contributes to the solid state bonding of the forged specimens and the concentration distributions in the pure $\mathrm{Mg}$ deposition coating layer.

(3) When the solid recycling process using hot extrusion at $673 \mathrm{~K}$ was carried out, the recycled specimen showed almost the same tensile properties as the virgin extruded specimen.

\section{Acknowledgements}

H.T. and M.M. gratefully acknowledge Grant-in-Aid for Scientific Research on Priority Areas (B) of "The priority Group of Platform Science and Technology for Advanced Magnesium Alloys", Ministry of Education, Culture, Sports, Science and Technology in Japan. Also, Y.C. gratefully acknowledges the financial support by Industrial Technology Research Grant Program in 2002 from the New Energy and Industrial Technology Development Organization (NEDO) in Japan.

\section{REFERENCES}

1) E. Aghion and B. Bronfin: Mater. Sci. Forum 350-351 (2000) 19-28.

2) B. Landkof: Proc. Magnesium Alloys and Their Applications, ed. by K. U. Kainer, (WILEY-VCH Verlag GmbH, Weinheim, 2000) pp. $168-172$.
3) O. Tsukamoto: ALUTOPIA 32 (No. 4) (2002) 16-21.

4) J. F. King, A. Hopkins and S. Thistlethwaite: Proc. the Third Int. Magnesium Conf., ed. by G. W. Lorimer, (The University Press Cambridge, UK, 1997) pp. 51-61.

5) E. Sato: SOKEIZAI 40 (No. 10) (1999) 1-9.

6) T. Takenaka, T. Fujita, S. Isazawa and M. Kawakami: Mater. Trans. 42 (2001) 1249-1253.

7) Y. Tamura, T. Haitani, N. Kono, T. Motegi and E. Sato: J. JILM 48 (1998) 237-241.

8) H. Tateishi, M. Inoue, S. Kamado, Y. Kojima, T. Itoh and M. Sugama: J. JILM 48 (1998) 19-24.

9) M. Mabuchi, K. Kubota and K. Higashi: Mater. Trans., JIM 36 (1995) 1249-1254.

10) Y. Chino, K. Kishihara, K. Shimojima, Y. Yamada, Cui'e Wen, H. Iwasaki and M. Mabuchi: J. Japan Inst. Metals 65 (2001) 621-626.

11) Y. Chino, K. Kishihara, K. Shimojima, H. Hosokawa, Y. Yamada, Cui'e Wen, H. Iwasaki and M. Mabuchi: Mater. Trans. 43 (2002) 2437-2442.

12) A. Yamamoto, A. Watanabe, K. Sugahara, H. Tsubakino and S. Fukumoto: Scr. Mater. 44 (2000) 1039-1042.

13) A. Yamamoto, A. Watanabe, K. Sugahara, S. Fukumoto and H. Tsubakino: Mater. Trans. 42 (2001) 1237-1242.

14) M. Inoue, M. Iwai, K. Matuzawa, S. Kamado and Y. Kojima: J. JILM. 48 (1998) 257-262.

15) S. Fukumoto, M. Tsukamoto, A. Yamamoto and H. Tsubakino: Collected Abstracts of the 2002 Spring Meeting of the Japan Inst. Metals (2002) p. 69.

16) P. Shewmon: Diffusion in Solid, (The Minerals, Metals \& Materials Society, Pennsylvania, 1989), p. 9.

17) Japan magnesium association ed.: Handbook of Advanced Magnesium Technology, (Kallos Publishing Co., Ltd., Tokyo, 2000) pp. 131-136.

18) H. J. Frost and M. F. Ashby: Deformation-Mechanism Maps, (Pargamon Press, Oxford, 1982) p. 44.

19) H. J. Frost and M. F. Ashby: Deformation-Mechanism Maps, (Pargamon Press, Oxford, 1982) pp. 6-16.

20) J. Pilling and N. Ridley: Superplasticty in Crystalline Solids, (The Institute of Metals, London, 1989), p. 175.

21) C. Kittel: Introduction to Solid State Physics, 7th ed., (Willy, New York, 1996), p. 585.

22) T. Mohri, M. Mabuchi, H. Iwasaki, T. Aizawa and K. Higashi: Mater. Sci. Eng. A290 (2000) 139-144. 